\title{
Development and Validation of Stability Indicating HPTLC Method for the Determination of Metformin Hydrochloride and Benfotiamine in Bulk and Combined Dosage Form
}

\author{
Ram Suresh Sakhare*, Sanjay Sudhakar Pekamwar, Deepak Prabhakar Mohkare \\ Department of Pharmaceutical Chemistry, School of Pharmacy, S.R. T. M. University, Nanded, Maharashtra, INDIA.
}

\begin{abstract}
Context: A Simple, selective, precise, and Stability indicating High Performance Thin Layer Chromatography (HPTLC) method of analysis of Metformin Hydrochloride (MET) and Benfotiamine (BENT) both as a bulk drug and in their combined formulation has been developed. Method: The basic aim of this method is to separate both the drugs by HPTLC and measure their spots at $249 \mathrm{~nm}$. The separation was carried out on TLC aluminium sheets of silica gel 6OF 254 using Benzene: Methanol: Triethylamine (8.5:1:0.5, v/v/v) as a mobile phase. Stability of MET and BENT was carried out by forced degradation study. Result: MET and BENT gave distinct and well defined peak at Rf 0.26 and 0.72 , respectively. Calibration curves were linear in range of 500-3000 and 75-450 ng/spot for MET and BENT, respectively. Method was successively applied to tablet formulation. Stability study shows that the chromatograms of samples degraded with acid, base, hydrogen peroxide, light and dry heat showed well separated spots of pure MET and BENT as well as some additional peaks at different RF values. Conclusion: The HPTLC method was also able to selectively quantitate Metformin hydrochloride and Benfotiamine in presence of their degradation products obtained in forced degradation study. Hence, the method can be used as stability indicating. The method was validated as per $\mathrm{ICH}$ guidelines and it is applied for the analysis of pharmaceutical dosage form containing these two drugs.
\end{abstract}

Key words: HPTLC, MET, BENT, Method validation, Forced Degradation, Stability Indicating.

\section{INTRODUCTION}

Metformin hydrochloride (MET) is chemically $\mathrm{N}, \mathrm{N}$-dimethylimidodicarbonimidic diamide hydrochloride (1,1-dimethylbiguanide hydrochloride) which suppresses the excessive hepatic glucose production helpful for improving glucose clearance from the body. It is official in Indian Pharmacopoeia, ${ }^{1}$ British Pharmacopoeia, ${ }^{2}$ European Pharmacopoeia, ${ }^{3}$ and United States Pharmacopoeia; ${ }^{4}$ A literature survey revealed that there are different methods are available which can estimate the Metformin Hydrochloride in their pharmaceutical dosage form e.g. Spectrophotometry, ${ }^{5-8}$ HPLC, ${ }^{9-13}$ LC-MS/MS, ${ }^{14}$ ion pairing HPLC, ${ }^{15}$ Stability indicating HPTLC, ${ }^{16,17}$ Stability indicating P-HPLC, ${ }^{18-24}$ LC-MS. Benfotiamine (S-benzoylthiamine O-monophosphate) is a member of allithiamines group which is a synthetic S-acyl derivative of thiamine (vitamin- B1). It is a lipid-soluble form of the Vitamin B-1, prescribed for treating painful nerve conditions by blocking AGEs (Advanced Glycation End products). Literature survey reveals that few HPLC methods have been reported for the estimation of benfotiamine individually and combination with other drugs ${ }^{25-27}$ The chemical
Submission Date: 28-11-2016; Revision Date: 02-03-2017; Accepted Date: 14-03-2017

DOI: 10.5530/ijper.51.2s.44 Correspondence: Ram S. Sakhare, School of Pharmacy, SRTM University, Nanded 431 606, Maharashtra, INDIA. Mobile No: 919975111037 E mail: ramsakhare@rediffmail.com

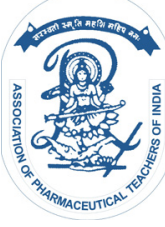

www.ijper.org 
structures of both drugs are shown in Figure 1 and Figure 2.

However no references have been found for stability indicating HPTLC method for simultaneous estimation of Metformin Hydrochloride and Benfotiamine. The International Conference on Harmonization (ICH) stability test guideline requires that analytical test procedures used for samples should be stability indicating and validated. ${ }^{28-30}$ The present work describes new method for simultaneous estimation of Metformin Hydrochloride and Benfotiamine.

\section{MATERIALS AND METHODS Materials}

Active pharmaceutical ingredient (API) working standards of Metformin $\mathrm{HCl}$ and Benfotiamine were received as a gift sample from Alkem Pharmaceuticals Ltd., Mumbai, and Aquatic Remedies Pvt. Ltd., Hyderabad, respectively. All the reagents used were of analytical grade (S. D. Fine Chemicals, Mumbai, India) and used without further purification.

\section{Instrumentation and Chromatographic conditions}

The samples were applied in the form of bands of width $6 \mathrm{~mm}$ with $100 \mu \mathrm{l}$ sample syringe on precoated silica gel aluminium plate $60 \mathrm{~F}-254(20 \mathrm{~cm} \times 10 \mathrm{~cm})$ with $250 \mu \mathrm{m}$ thickness; (E. MERCK, Darmstadt, Germany) using a Camag Linomat V sample applicator. The plates were washed prior to chromatography with methanol and then activated at $110^{\circ} \mathrm{C}$ for $15 \mathrm{~min}$. A constant application rate of $150 \mathrm{nl} / \mathrm{sec}$ was employed and space between two bands was $85 \mathrm{~mm}$. The slit dimension was kept at $6 \mathrm{~mm} \times 0.45 \mathrm{~mm}$. The mobile phase consists of Benzene: Methanol: Triethylamine (8.5:1:0.5, v/v/v). Linear ascending development was carried out in $20 \mathrm{~cm} \times 10 \mathrm{~cm}$ twin trough glass chamber (Camag, Muttenz, Switzerland). The optimized chamber saturation time for mobile phase was $20 \mathrm{~min}$, at temperature $\left(25^{\circ} \mathrm{C} \pm 5 \%\right)$; the chromatogram was run and its lenght was found to be $8 \mathrm{~cm}$ and TLC plates were air dried. Densitometric scanning was performed on Camag TLC Scanner III controlled with CATS 1.4.2 software at $249 \mathrm{~nm}$. The source of radiation utilized was deuterium lamp. Evaluation was performed using peak area with linear regression.

\section{Preparation of Standard solutions and calibration graphs}

Combined standard stock solution containing $500 \mu \mathrm{g} / \mathrm{ml}$ of MET and $75 \mu \mathrm{g} / \mathrm{ml}$ of BENT was prepared in methanol. Calibration standards were spotted by using Camag Hamilton $100 \mu \mathrm{l}$ syringe with the help of auto- matic sample applicator Linomat V on TLC plates that gave concentration 500-3000 ng/spot of MET and 75-450 ng/spot of BEN, respectively. Each concentration was spotted six times on the TLC plates. The plates were developed using previously described mobile phase. The calibration curve was plotted as peak areas versus corresponding concentration.

\section{Method Validation}

\section{Precision}

Repeatability of the method was assessed by spotting $500 \mathrm{ng} / \mathrm{spot}$ for MET and $75 \mathrm{ng} / \mathrm{spot}$ for BENT of drug solution six times on a TLC, followed by development of plate. The intra-day precision $(\% \mathrm{RSD})$ was assessed by analyzing standard drug solutions within the calibration range, three times on the same day. Inter-day precision (\%RSD) was assessed by analyzing drug solutions within the calibration range on three different days over a period of a week.

\section{Limit of detection and limit of quantification}

In order to determine detection and quantification limit, concentrations in the lower part of the linear range of the calibration curve were used. Stock solution of MET and BENT was prepared and different volume of stock solution in the range 500-3000 ng of MET and 75-450 ng for BENT were spotted triplicate. The amount of both the drugs by spot versus average response (peak area) was graphed and the equation for this was determined. The standard deviations (S.D.) and average of standard deviations was calculated (A.S.D.). Detection limit was calculated by $(3.3 \times$ Standard deviation $) / b$ and quantification limit was calculated by $(10 \times$ Standard deviation)/b, where " $b$ " corresponds to the slope obtained in the linearity study of method.

\section{Specificity}

Specificity of the method was ascertained by analysing standard drug and sample. The mobile phase resolved both the drugs very efficiently, as shown in (Figure 2). The spot for MET and BENT was confirmed by comparing the RF and spectra of the spot with that of standard.

\section{Accuracy}

Recovery study was carried out by over spotting $80 \%$, $100 \%$ and $120 \%$ of the standard drug solution of MET and BENT and the mixtures were reanalyzed by the proposed method. The experiment was conducted in triplicate. This was done to check the recovery of the drug at different levels in formulations. 


\section{Robustness}

Robustness was studied in six replicate at the concentration level of $500 \mathrm{ng} / \mathrm{spot}$ for MET and $75 \mathrm{ng} / \mathrm{spot}$ for BENT. Robustness of the developed method was evaluated by the analysis of sample solution after making small changes in mobile phase composition and mobile phase saturation time. The low value of \% RSD shows that the method is robust and that a slight change in mobile phase volume and mobile phase saturation time does not affect the results.

\section{Analysis of MET and BENT in marketed formulation}

To determine the content of MET and BENT simultaneously in conventional tablets (label claim 500mg MET and $75 \mathrm{mg}$ BENT); twenty tablets were accurately weighed, average weight was determined and ground to a fine powder. A quantity of powder equivalent to $500 \mathrm{mg} \mathrm{MET}$ and $75 \mathrm{mg}$ BENT was transferred into $100 \mathrm{ml}$ volumetric flask containing $50 \mathrm{ml}$ of methanol, sonicated for $15 \mathrm{~min}$ and diluted up to the mark with the same solvent. The resulting solution was filtered using $0.45 \mu \mathrm{m}$ filter (Millifilter, MA). $0.4 \mu \mathrm{L}$ of the above solution was applied on TLC plates followed by development and scanning as described in section 2.2. The analysis was repeated for six times. MET and BENT gave sharp and well defined peaks at Rf 0.26 and 0.72 , respectively, when scanned at $249 \mathrm{~nm}$. The results are shown in Table 1 indicate that there was no interference from the excipients commonly present in the tablets.

\section{Forced degradation of MET and BENT Acid and Base induced degradation}

From the standard solution of MET $(5000 \mu \mathrm{g} / \mathrm{ml})$, $1 \mathrm{ml}$ of solution was mixed with $1 \mathrm{ml}$ of $0.1 \mathrm{~N} \mathrm{HCl}$ and $8 \mathrm{ml}$ of methanol. The solution was refluxed at $80^{\circ} \mathrm{C}$ for $4 \mathrm{hrs} .3 \mu \mathrm{l}$ volume of this solution was applied on TLC plate to get concentration $1500 \mathrm{ng} / \mathrm{band}$. Similarly solution having final concentration $75 \mathrm{ng} / \mathrm{band}$ for BENT was prepared from the standard stock solution $(750 \mu \mathrm{g} / \mathrm{ml}$ ) and $3 \mu \mathrm{l}$ volume of resulting solution was applied on TLC plate. The chromatograms were run as described in section 2.2. and it is shown in Figure 4-7.

\section{Hydrogen peroxide-induced degradation}

From the standard solution of MET $(5000 \mu \mathrm{g} / \mathrm{ml})$, $1 \mathrm{ml}$ of solution was mixed with $1 \mathrm{ml}$ of $3 \% \mathrm{H}_{2} \mathrm{O}_{2}$ and $8 \mathrm{ml}$ of methanol. The solution was refluxed at $80^{\circ} \mathrm{C}$ for $4 \mathrm{hrs.} 3 \mu \mathrm{l}$ volume of this solution was applied on TLC plate to get concentration $1500 \mathrm{ng} / \mathrm{band}$. Similarly solution having final concentration $75 \mathrm{ng} / \mathrm{band}$ for BENT was prepared from the standard stock solution $(750 \mu \mathrm{g} / \mathrm{ml})$ and $3 \mu \mathrm{l}$ volume of resulting solution was applied on TLC plate. The chromatograms were run as described in section 2.2 and it is shown in Figure 8-9.

\section{Dry heat degradation}

Dry heat studies were performed by keeping drug sample as individual in oven $\left(80^{\circ} \mathrm{C}\right)$ for a period of 2 hour. Samples were withdrawn, dissolved in methanol and diluted appropriately to get concentration of $500 \mu \mathrm{g} / \mathrm{ml}$ for MET and $75 \mu \mathrm{g} / \mathrm{ml}$ for BENT. $3 \mu \mathrm{l}$ volumes were applied on TLC plate to get concentration $1500 \mathrm{ng} /$ band for MET and $450 \mathrm{ng} / \mathrm{band}$ for BENT. The resulting solutions were applied on TLC plate and analysed under optimized chromatographic conditions. The chromatograms were run as described in section 2.2 and it is shown in Figure 10-11.

\section{Photolytic degradation}

Photolytic studies were also carried out by exposure of drug individually to UV light up to 200 watt hours/ square meter for period of $4 \mathrm{hrs}$. Sample was weighed, dissolved and diluted get respective concentrations. $3 \mu \mathrm{l}$ of solutions were spotted. The chromatograms were run as described in section 2.2. and it is shown in Figure 12-13.

\section{RESULTS AND DISCUSSION Optimization of HPTLC method}

Initially, trials were carried out using chloroform: methanol, toluene: methanol, methanol: ethyl Acetate, benzene: methanol: triethylamine in various proportions, to obtain the satisfactory resolution between the two drugs along with desired system suitability parameters. After several trials, benzene: methanol: triethylamine (8.5: 1: 0.5, $\mathrm{v} / \mathrm{v} / \mathrm{v}$ ) selected as optimum mobile phase with chamber saturation time $20 \mathrm{~min}$, which gave good resolution and sharp peaks for both the drugs. Other chromatographic conditions like run length, sample application volume, sample application positions, distance between tracks, detection wavelength, were optimized to give reproducible $\mathrm{R}_{\mathrm{f}}$ values and symmetrical peak shape for the drug peak.

\section{Validation of the method}

\section{Linearity}

Linearity responses for MET and BENT were assessed in the concentration range 500-3000 ng/spot and 75-450 $\mathrm{ng} / \mathrm{spot}$, respectively. The linear equations for the calibration plots were $y=1.279 \mathrm{x}+3026$ and $\mathrm{y}=8.927 \mathrm{x}+$ 605.4, with correlation coefficient (r) being 0.999 
<smiles>C/C(=C(\CCOP(=O)(O)O)SC(=O)c1ccccc1)N(Cc1cnc(C)nc1)C(=O)/C=N\C(=N)N(C)C</smiles>

(B)

Figure 1: Chemical structures of MET (A) and BENT (B)

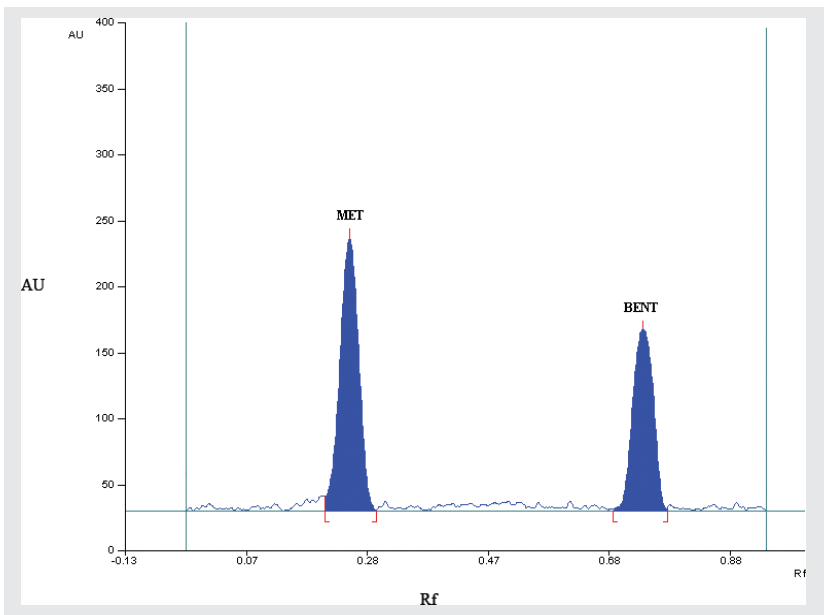

Figure 2: Densitogram of standard MET and BENT

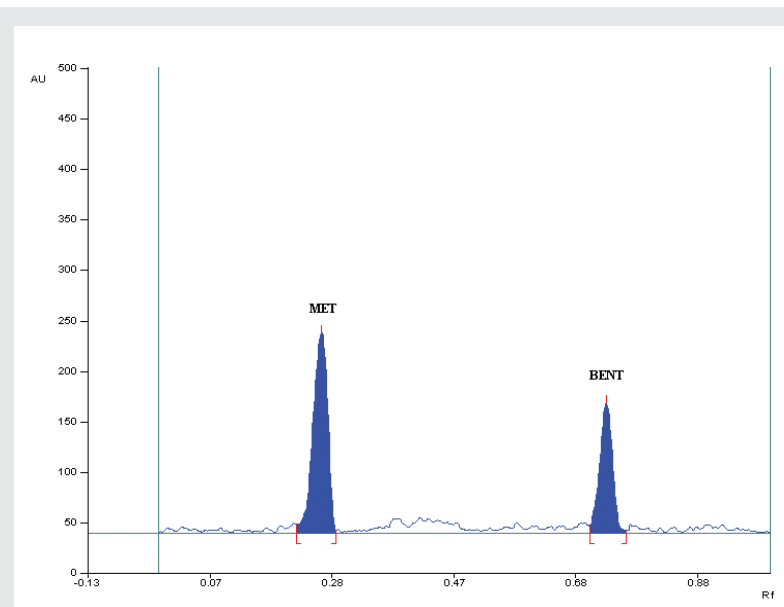

Figure 3: Representative densitogram of mixed standard solution MET(1500 ng/band, $\left.R_{f}=0.26 \pm 0.04\right)$ and BENT $(225$ $\left.\mathrm{ng} / \mathrm{band}, \mathrm{R}_{\mathrm{f}}, 0.72 \pm 0.03\right)$

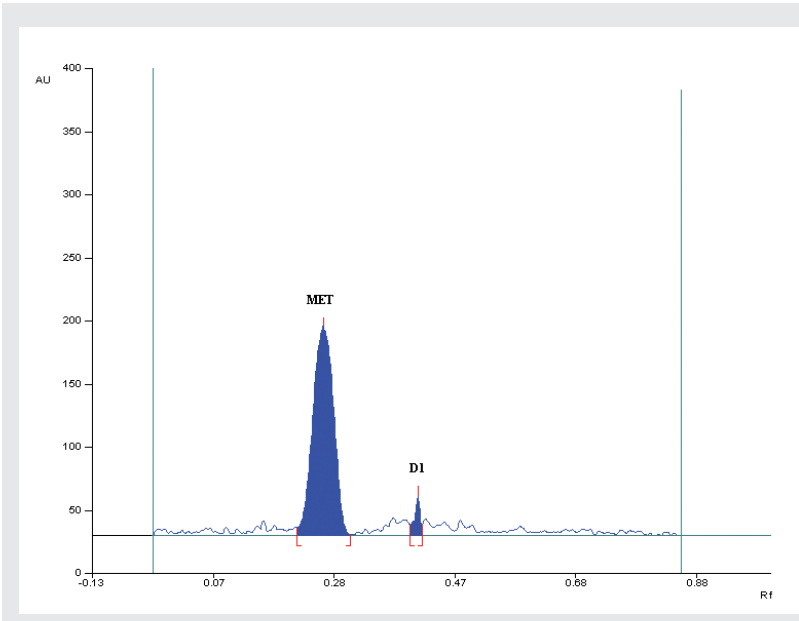

Figure 4: Representative densitogram of MET after acid degradation $\mathrm{D} 1(\mathrm{Rf}=\mathbf{0 . 4 4})$

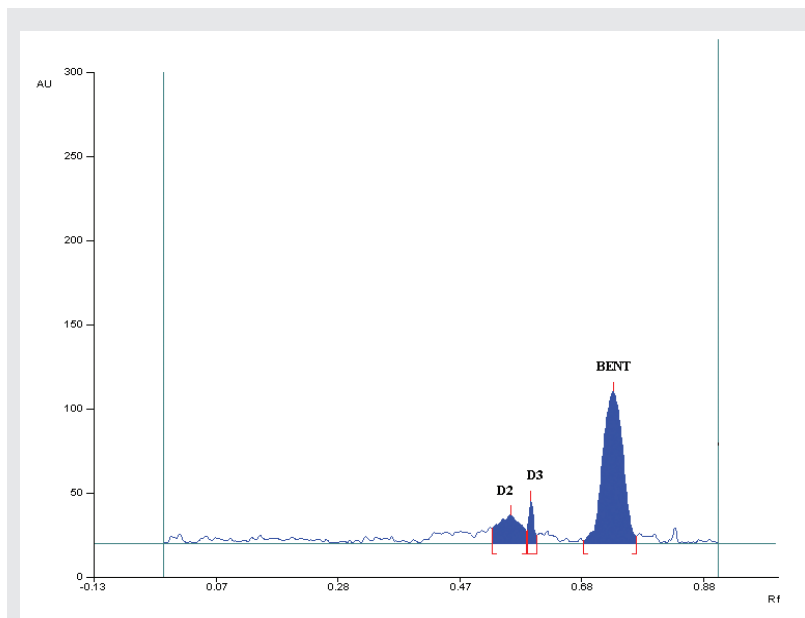

Figure 5: Representative densitogram of BENT after acid degradation D2 $(R f=0.54)$ and D3 $(R f=0.59)$

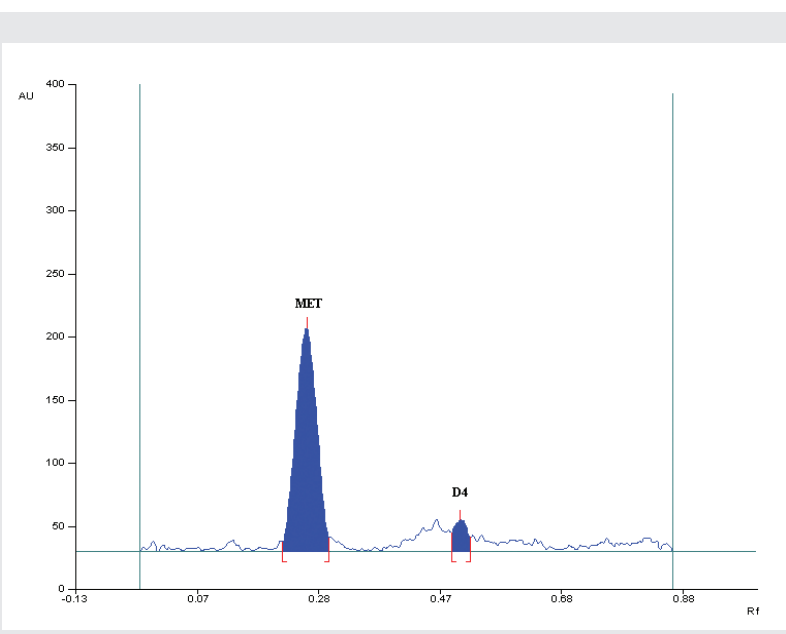

Figure 6: Representative densitogram of MET after alkaline hydrolysis $\mathrm{D} 4(\mathrm{Rf}=\mathbf{0 . 5 1})$ 


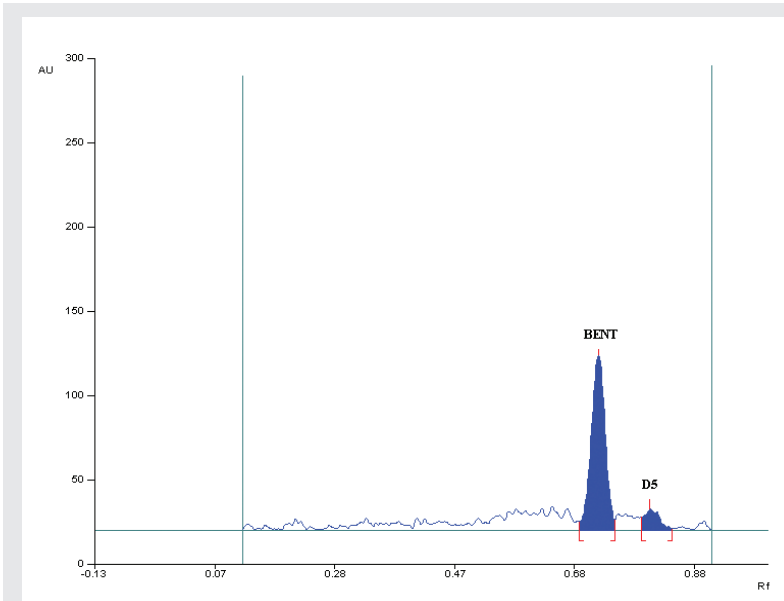

Figure 7: Representative densitogram of BENT after alkaline hydrolysis D5 $(\mathrm{Rf}=\mathbf{0 . 8 2})$

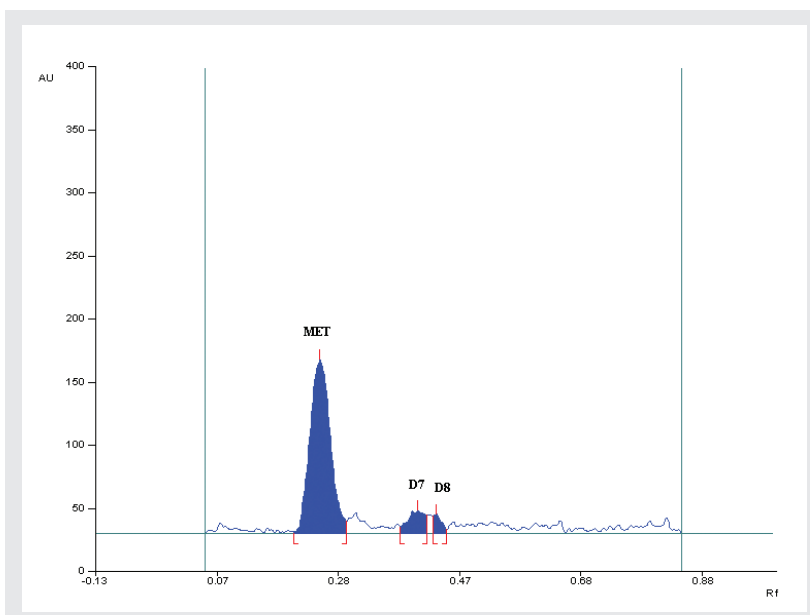

Figure 8: Representative densitogram of MET after oxidative degradation $\mathrm{D} 7(\mathrm{Rf}=0.40)$ and $\mathrm{D8}(\mathrm{Rf}=0.45)$

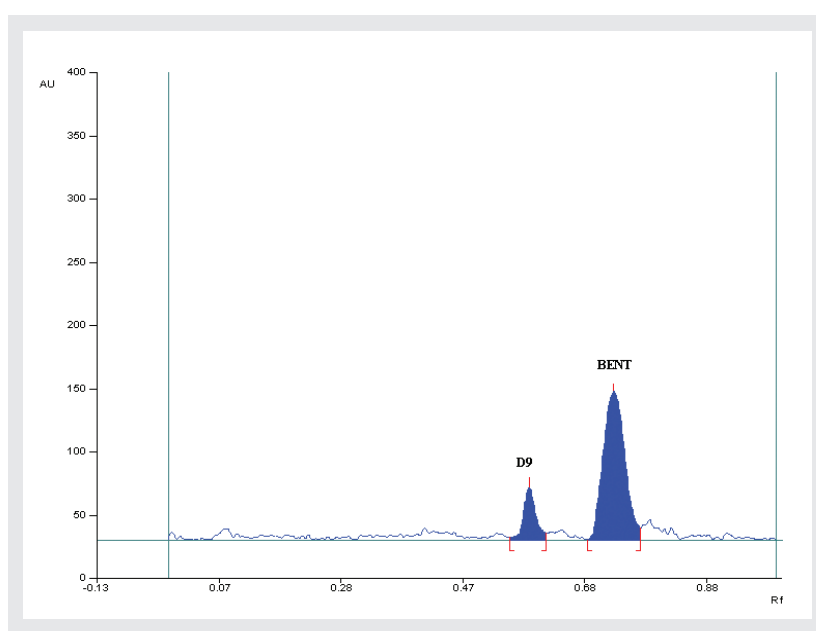

Figure 9: Representative densitogram of BENT after oxidative degradation $\mathrm{D9}(\mathrm{Rf}=\mathbf{0 . 5 8})$

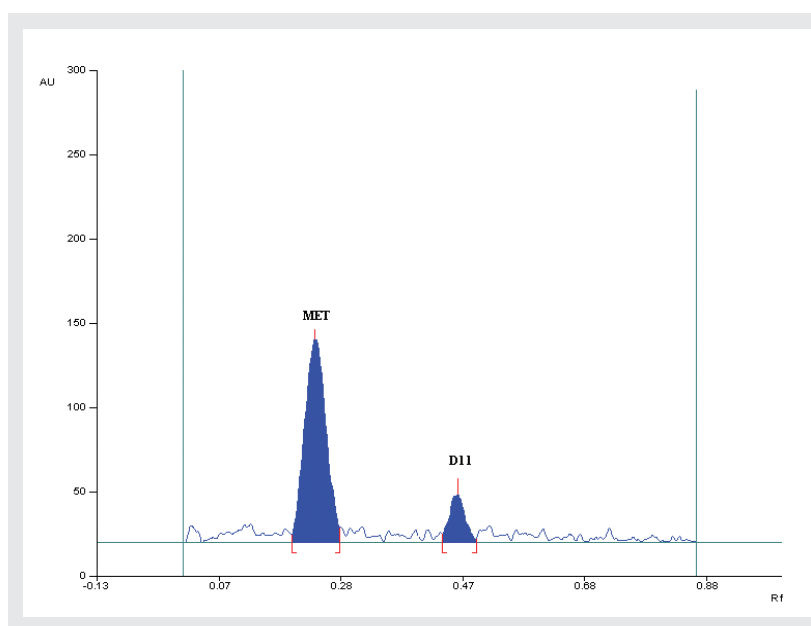

Figure 10: Representative densitogram of MET after dry heat degradation D11 $(\mathrm{Rf}=\mathbf{0 . 4 7})$

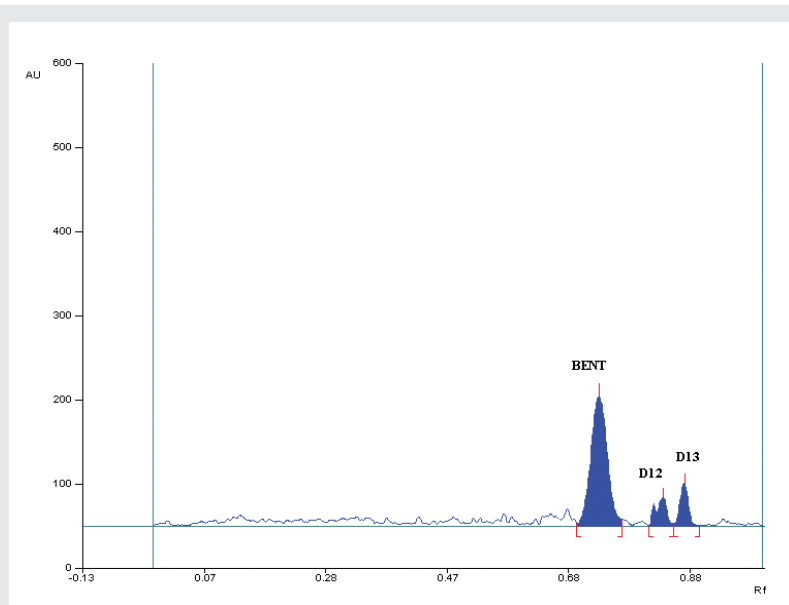

Figure 11: Representative densitogram of BENT after dry heat degradation D12 $(R f=0.83)$ and $D 13(R f=0.88)$

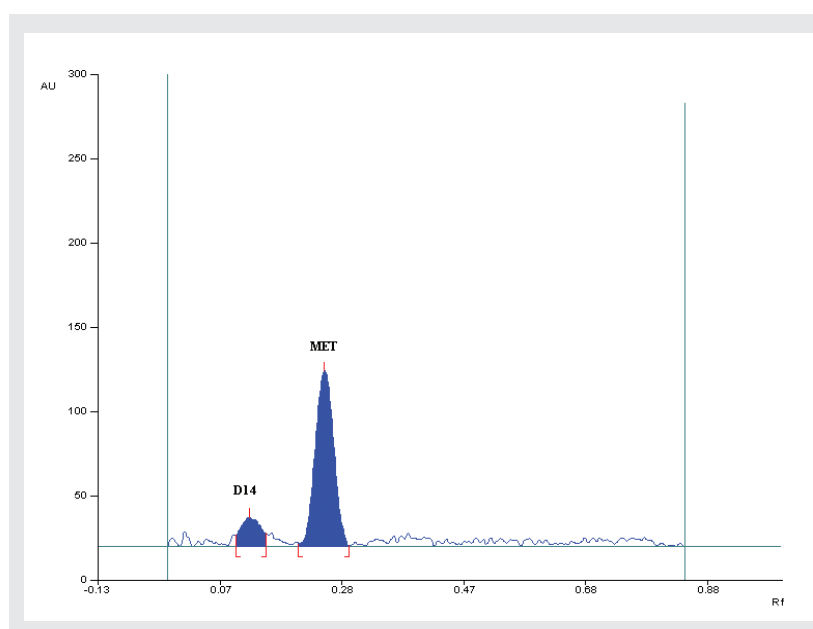

Figure 12: Representative densitogram of MET after exposing to light D14 $(\mathrm{Rf}=\mathbf{0 . 1 4})$ 
and 0.999 for MET and BENT, respectively. Range was established with five replicate readings of each concentration.

\section{Precision}

Precision of the method was determined in the terms of intraday and interday variations ( $\%$ RSD). Intraday precision ( $\%$ RSD) was assessed by analysing standard drug solutions within the calibration range, three times on the same day, $\%$ RSD was found to be $0.56-0.64$ for MET and 0.69-1.07 for BENT.

Interday precision ( $\%$ RSD) was assessed by analysing standard drug solutions within the calibration range on three different days over a period of week. \% RSD

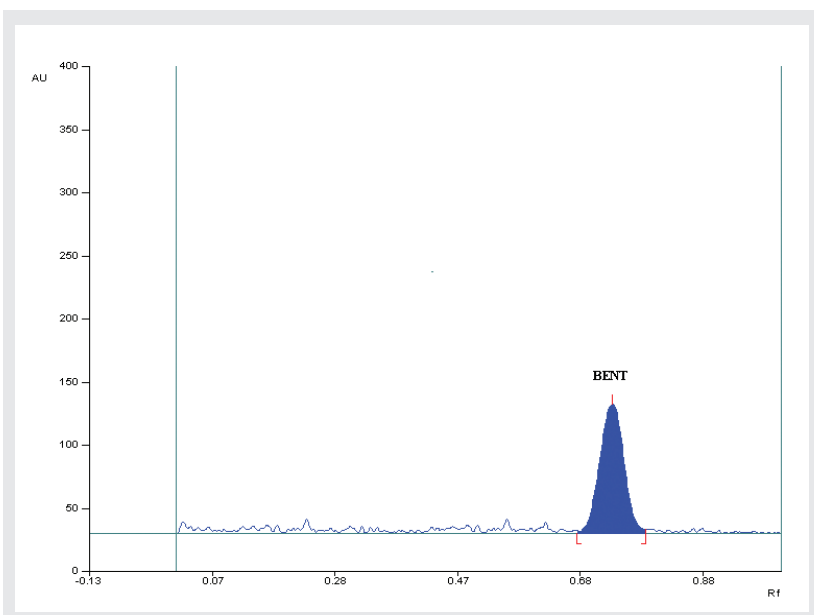

Figure 13: Representative densitogram of BENT after exposing to light was found to be $0.70-0.84$ for MET and 1.14-1.43 for BENT. This indicates that adequate preciseness of the method.

\section{Limit of detection and limit of quantitation}

Detection limit and quantification limit was calculated by the method as described in Section 2.4.2. The LOQ and LOD for MET were $426 \mathrm{mg}$ and $141 \mathrm{mg} / \mathrm{spot}$. For BENT, LOQ and LOD were found to be $59 \mathrm{mg}$ and $20 \mathrm{mg}$, respectively. This indicates that adequate sensitivity of the method.

\section{Accuracy}

To the preanalysed sample a known amount of standard solution of pure drug (MET and BENT) was over spotted at three different levels. These solutions were subjected to reanalyze by the proposed method and results of the same are shown in Table 2.

\section{Robustness}

The standard deviation of peak areas was calculated for each parameter and \%RSD was found 1.18-1.28. The low $\%$ RSD indicates robustness of the method. The summary of Robustness parameters were listed in Table 3.

\section{Repeatability}

Repeatability of sample application was assessed by spotting (300 ng/spot) of drug solution seven times on a TLC, followed by development of plate and recording the peak area for seven spots. The $\% \mathrm{RSD}$ for peak area

\begin{tabular}{|c|c|c|c|}
\hline \multicolumn{4}{|c|}{ Table 1: Assay of tablet formulation. } \\
\hline Component & Label claim $(\mathbf{m g})$ & \%Label claim* & \%RSD \\
\hline MET & 500 & 99.98 & 1.06 \\
\hline BENT & 75 & 99.41 & 1.58 \\
\hline
\end{tabular}

* mean of six estimations

$\%$ RSD-\% Relative Standard Deviation

\begin{tabular}{|c|c|c|c|c|}
\hline \multicolumn{5}{|c|}{ Table 2: Results of recovery studies. } \\
\hline \multirow{2}{*}{ Component } & $\begin{array}{c}\text { Label claim } \\
\text { (mg/tablet) }\end{array}$ & $\begin{array}{c}\text { (\%) Amount of } \\
\text { standard drug added }\end{array}$ & \% Drug recovered * & \%RSD \\
\hline \multirow{3}{*}{ MET } & 500 & 80 & 99.82 & 0.6342 \\
\cline { 2 - 5 } & 500 & 100 & 100.08 & 0.6263 \\
\cline { 2 - 5 } & 500 & 120 & 100.26 & 0.8535 \\
\hline \multirow{3}{*}{ BENT } & 75 & 80 & 100.26 & 1.3614 \\
\cline { 2 - 5 } & 75 & 100 & 99.88 & 0.6372 \\
\cline { 2 - 5 } & 75 & 120 & 100.31 & 0.6231 \\
\hline
\end{tabular}

* mean of three estimations at each level. $\%$ RSD- \% Relative Standard Deviation 


\begin{tabular}{|c|c|c|c|c|}
\hline \multicolumn{4}{|c|}{ Table 3: Robustness of MET and BENT } \\
\hline \multirow{2}{*}{ Sr. No. } & Parameters & Variation & \multicolumn{2}{c|}{$\%$ R.S.D* } \\
\cline { 3 - 5 } & & MET & BENT \\
\hline 1. & Mobile phase composition & $\begin{array}{c} \pm \% \\
\text { Methanol }\end{array}$ & 1.18 & 1.28 \\
\hline 2. & Change in wavelength & $\pm 1 \mathrm{~nm}$ & 0.75 & 0.53 \\
\hline
\end{tabular}

*Average of three determinations

\begin{tabular}{|c|c|c|}
\hline Parameter & MET & BENT \\
\hline Linearity range $\left(\mathrm{ng} / \mathrm{spot}^{-1}\right)$ & $500-3000$ & $75-450$ \\
\hline Correlation coefficient & 0.999 & 0.999 \\
\hline Limit of Detection $\left(\mathrm{ng} / \mathrm{spot}^{-1}\right)$ & 140.74 & 19.60 \\
\hline Limit of quantitation $\left(\mathrm{ng} / \mathrm{spot}^{-1}\right)$ & 426.48 & 59.39 \\
\hline$\%$ Recovery $(n=9)$ & 100.05 & 100.15 \\
\hline \multicolumn{3}{|l|}{ Precision (\%R.S.D.) } \\
\hline Interday (n=3) & $0.70-0.84$ & $1.14-1.43$ \\
\hline Intraday $(n=3)$ & $0.56-0.64$ & $0.69-1.07$ \\
\hline Robustness & Robust & Robust \\
\hline Specificity & Specific & Specific \\
\hline
\end{tabular}

\begin{tabular}{|c|c|c|c|c|c|c|}
\hline \multirow{2}{*}{ Sample exposure condition } & \multicolumn{2}{|c|}{$\begin{array}{c}\text { Number of degradation } \\
\text { products (Rf values) }\end{array}$} & \multicolumn{2}{|c|}{ Drug remained } & \multicolumn{2}{|c|}{ Recovery (\%) } \\
\hline & MET & BENT & MET (1500 ng/spot) & $\begin{array}{c}\text { BENT } \\
(750 \mathrm{ng} / \mathrm{spot})\end{array}$ & MET & BENT \\
\hline $0.1 \mathrm{~N} \mathrm{HCl}, 4 \mathrm{~h}$, Reflux at $80^{\circ} \mathrm{C}$ & $1(0.44)$ & $2(0.54,0.59)$ & 1387.95 & 574.87 & 88.53 & 76.64 \\
\hline $0.1 \mathrm{~N} \mathrm{NaOH}$, Reflux $4 \mathrm{~h}$ at $80^{\circ} \mathrm{C}$ & $1(0.51)$ & 0.82 & 1297.80 & 652.87 & 86.52 & 87.05 \\
\hline $3 \% \mathrm{H}_{2} \mathrm{O}_{2}$ Reflux at $80^{\circ} \mathrm{C}$ & $2(0.40,0.45)$ & 0.58 & 1173.45 & 552.82 & 78.23 & 73.71 \\
\hline Photo & $1(0.14)$ & - & 1289.80 & 648.37 & 85.95 & 86.45 \\
\hline Heat $80^{\circ} \mathrm{C}$ for $2 \mathrm{~h}$ & $1(0.47)$ & $2(0.83,0.88)$ & 1289.25 & 540.82 & 85.32 & 72.06 \\
\hline
\end{tabular}

values of MET and BENT was found to be 1.21 and 0.57 , respectively. The summary of validation parameters were listed in Table 4.

\section{Stability-indicating Property}

The chromatogram of samples degraded with acid, base, hydrogen peroxide and light showed well separated spots of pure MET and BENT as well as some additional peaks at different $\mathrm{Rf}$ values. The number of degradation product with their Rf values, content of MET and BENT remained, and percentage recovery were represented in Table 5 .

\section{CONCLUSION}

The proposed developed HPTLC method is validated as per ICH guidelines. The low value of $\%$ RSD indi- cates high degree of precision of method. The results of the recovery studies performed shows high degree of accuracy for developed method. So it can be concluded that proposed HPTLC method is accurate, precise, specific and can be employed successfully for estimation of MET and BENT in pharmaceutical dosage forms.

\section{ACKNOWLEDGEMENT}

The authors are thankful to Alkem Pharmaceuticals Ltd., Mumbai, and Aquatic Remedies Pvt. Ltd., Hyderabad for providing Metformine hydrochloride and Benfotiamine drug as gift sample. Authors are also thankful to Director, School of Pharmacy, Swami Ramanand Teerth Marathwada University, Nanded, for providing necessary facilities. 


\section{CONFLICT OF INTEREST}

No conflict of interest are declared.

\section{ABBREVIATION USED}

MET: Metformine Hydrochloride; BENT: Benfotiamine; Rf: Retention Factor; ICH: International conference on Harmonization; LOD: Limit of Detection; LOQ: Limit of Quantitation; S.D.: standard Deviation; \%R.S.D.: \% Relative Standard Deviation.

\section{REFERENCES}

1. Indian Pharmacopoeia, Government of India, Ghaziabad. The Indian Pharmacopoeia Commission, Vol.2, 2007, 1358.

2. British Pharmacopoeia, Vol.1 and 2, Her. Majesty's Stationary Office, London, UK, 2009,3813.

3. European Pharmacopoeia, 3rd Edition, Council of Europe, France, 1997,55.

4. The United States Pharmacopoeia, 31st Revision, US Pharmacopoeial convention, Inc. Rockville, MD., 2008, 2640.

5. Sulakshana1 S, Sankar R, Nageswar VR, Harithanandini T, Dastagiri Reddy Y and Pushpalatha1E. Spectrophotometric method development and comparative study of Metformin HCL in API and solid dosage form using uv-spectroscopy. International Journal of Pharmacy and Biological Sciences 2015;5(2):323-30.

6. Patel N, Patel KR. Development and Validation of UV Spectrophotometric Method for Simultaneous Estimation of Metformin $\mathrm{HCL}$ and Repaglinide in Bilayer Tablet. Journal of Pharmaceutical Science and Bioscientific Research 2015;5(1):104-9.

7. Jani BR, Shah KV and Kapupara PP. Development and Validation of UV Spectroscopic First Derivative Method for Simultaneous Estimation of Dapagliflozin and Metformin Hydrochloride in Synthetic Mixture. Journal of Bioequivalence Studies 2015;1(1):102.

8. Mishra K, Soni H, Nayak G, Patel SS and Singhai AK. Method Development and Validation of Metformin Hydrochloride in Tablet Dosage form. E-Journal of Chemistry 2011;8(3):1309-13. https://doi.org/10.1155/2011/768014.

9. Nanaware DA, Bhusari VK, Dhaneshwar SR. Validated HPLC method for simultaneous quantitation of Benfotiamine and Metformin Hydrochloride in bulk drug and formulation. International Journal of Pharmacy and Pharmaceutical Sciences 2013;5(2):138-42.

10. Adithya BP, Vijayalakshmi M, Mahesh. Development and Validation of RPHPLC Method for the Simultaneous Estimation of Benfotiamine and Metformin hydrochloride in Tablet Dosage form. RGUHS J Pharm Sci.2012;2(4):87-91.

11. Patel MG, Patil PO, Bari SB. Validated RP-HPLC method for simultaneous estimation of Metformin Hydrochloride and Benfotiamine in bulk drug and in pharmaceutical dosage form. International Journal of Analytical and Bioanalytical Chemistry 2012; 2(3): 196-200

12. Madhukar A, Prince A, Vijay Kumar R, Sanjeeva $Y$, Jagadeeshwar K, Raghupratap D. Simple and sensitive analytical method development and validation of Metformin hydrochloride by RP-HPLC. International Journal of Pharmacy and Pharmaceutical Sciences 2011;3(3): 117-20.

13. Saikiran G. Method development of Metformin Hydrochloride by RP-HPLC. World Journal of Pharmacy and Pharmaceutical Sciences 2014;3(3):1149-59.

14. Reddy S, Ahmad I, Mukhopadhyay A and Thangam A. Development and Validation of a Method for Simultaneous Estimation of Metformin and Sitagliptin in Human Plasma by LC-MS-MS and Its Application in a Bioequivalence study. Journal of Chromatographic Science 2015;1-8. https:// doi.org/10.1093/chromsci/bmv055.

15. Udaykumar Rao B, Nikalje AP. Determination of gliclazide in a tablet dosage form in the presence of Metformin Hydrochloride by ion pair-reversed phase liquid chromatographic technique. African Journal of Pharmacy and Pharmacology2011;5(11):1331-7. https://doi.org/10.5897/AJPP10.106.
16. Pritam J, Devendra G, Anjali B, Surana S. Stability- Indicating HPTLC densitometric method for determination of Metformin Hydrochloride in tablet formulation. Journal of Pharmaceutical and Biosciences2013;1:51-8.

17. Rajasekaran A, Kavitha R, Arivukkarasu R. Development and validation of HPTLC method for simultaneous estimation and stability indicating study of Metformin HCL and linagliptin in pharmaceutical formulation. World Journal of Pharmaceutical Sciences2014;2(4):317-27.

18. Thanuja SV, Chandan RS, Tengli AR, Gurupadayya B M, Prathyusha W. Stability Indicating RP-HPLC Method for the Simultaneous Estimation of Metformin Hydrochloride, Pioglitazone Hydrochloride and Glibenclamide in Bulk and Pharmaceutical Dosage forms. IOSR Journal of Pharmacy and Biological Sciences 2014;9(1):124-33. https://doi.org/10.9790/30080914124133

19. Nagaraju $P$ and Ramanakanth MV. Validated stability indicating method for simultaneous estimation of Metformin $\mathrm{HcL}$ and acarbose in bulk and its combined tablet dosage form by RP-HPLC. Journal of Pharmaceutical Research 2014;13(3):80-4. https://doi.org/10.18579/jpcrkc/2014/13/3/78389.

20. Ramesh D and Habibuddin M. Stability Indicating RP-HPLC Method for the Simultaneous Determination of Atorvastatin Calcium, Metformin Hydrochloride, and Glimepiride in Bulk and Combined Tablet Dosage Form. Hindawi Publishing Corporation, International Scholarly Research Notices 2014:1-8.

21. Peraman R, Peruru KK, Yiragam PR and Gowra CS. Stability indicating RPHPLC method for simultaneous determination of Metformin hydrochloride and pioglitazone hydrochloride in dosage form. Malaysian Journal of Pharmaceutical Sciences 2014;12(1):33-46.

22. Raja A, Dhanalaxmi M, Banji D, Rao KNV, Kumar SD. Stability indicating RP-HPLC method development and validation of simultaneous estimation of Metformin and acarbose in bulk and pharmaceutical formulation. Asian Journal of Research in Biological and Pharmaceutical Sciences2015;3(2): $66-77$.

23. Mandal S, Patel B, Bose A, Swamy G, Pandit SN, Goli D. Stability indicating assay method by HPLC for simultaneous estimation of Metformin and glipizide in bulk and pharmaceutical dosage form. World Journal of Pharmacy Pharmaceutical Sciences 2015;4(6): 1410-31.

24. Yunoos M and Sankar DG. Stability indicating quantitative RP-HPLC method development and validation for simultaneous determination of Metformin hydrochloride and Saxagliptin in bulk and combined tablet dosage form. Journal of Chemical and Pharmaceutical Research 2015;7(4):346-55

25. Reddy S, Ahmad I, Mukhopadhyay A and Thangam S. Development and Validation of a Method for Simultaneous Estimation of Metformin and Sitagliptin in Human Plasma by LC-MS-MS and Its Application in a Bioequivalence study. Journal of Chromatographic Science Advance2015; $1-8$.

26. Adithya BP and Vijayalakshmi M. Development and validation of RPHPLC method for the estimation of Benfotiamine in bulk and dosage form. International Journal of Pharmaceutical, Chemical and Biological Sciences 2012;2(3):354-60.

27. Poongothai $\mathrm{S}$, Ilavarasan $\mathrm{R}$, Karrunakaran CM. Simultaneous and accurate determination of vitamins B1, B6, B12 and alphalipoic acid in multivitamin capsule by reverse-phase high performance liquid chromatographic method. International Journal of Pharmacy and Pharmaceutical Sciences 2010;2(4):133-9.

28. EMEA Guidelines. International Conference on Harmonization $(\mathrm{ICH})$ of Technical Requirements for the Registration of Pharmaceutical for Human Use. Stability testing of new drugs substance and products, Q1A (R2), 2003:1-18.

29. Bakshi M, Singh S. Development of validated stability-indicating assay methods - critical review. Journal of Pharmaceutical and Biomedical Analysis 2002;28:1011-40. https://doi.org/10.1016/S0731-7085(02)00047-X.

30. Sethi PD.HPTLC Quantitative Analysis of Pharmaceutical Formulation. New Delhi, CBS Publications 1996:162-165 


\section{Pictorial Abstract}

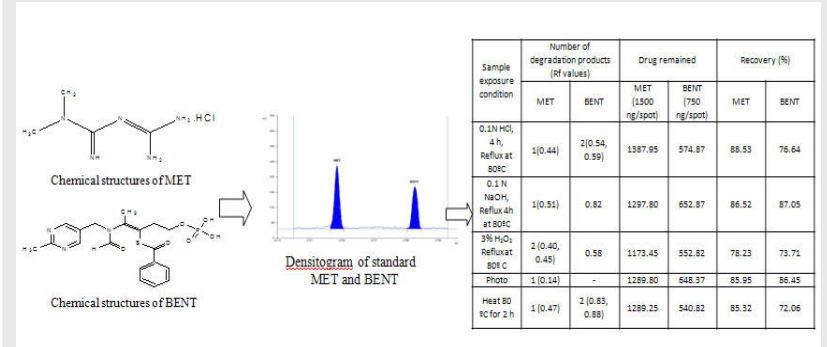

\section{About Authors}

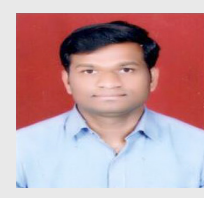

Mr. Ram Suresh Sakhare: Research Student, Department of Pharmaceutical Chemistry, School of Pharmacy, S.R.T.M.University, Nanded.

Dr. Sanjay S. Pekamwar: Professor, Department of Pharmaceutical Chemistry, School of Pharmacy, S.R.T.M.University, Nanded.

Mr.Deepak P. Mohkare: M.Pharm, Department of Pharmaceutical Chemistry, School of Pharmacy, S.R.T.M.University, Nanded.

\section{SUMMARY}

- Extensive literature survey revealed that no stability indicating HPTLC method has been reported so far for the simultaneous estimation of the MET and BENT in combined tablet dosage form. So the work was aimed at development and validation of a simple, accurate and precise stability indicating HPTLC method for simultaneous quantification of these compounds as bulk drugs and in combined tablet dosage form. Different mobile phases containing various ratios of Chloroform: methanol, Toluene: methanol, Methanol: Ethyl Acetate, Benzene: methanol: Triethylamine, Toluene: Methanol: Ethyl acetate were tried to achieve the separation of two drugs. Finally the mobile phase comprising Benzene: methanol: Triethylamine (8.5: $1: 0.5, v / v / v)$ was selected as optimal for obtaining well defined and resolved peaks for both the drugs. Results were found to be linear in the concentration range of 500-3000 $\mathrm{ng} / \mathrm{band}$ for MET and 75-450 $\mathrm{ng} / \mathrm{band}$ for BENT with high correlation coefficient. The recovery study results ranged from 99.82 to 100.26 for MET and 99.88 to 100.31 for BENT \%. The method was found to be accurate and precise, as indicated by recovery studies as recoveries were close to $100 \%$ and \% R.S.D. not more than 2 . Both the drugs were found to be susceptible to the stress conditions used when exposed to stress degradation as per ICH Guidelines.

Cite this article: Sakhare RS, Pekamwar SS, Mohkare DP. Development and Validation of Stability Indicating HPTLC method for the determination of Metformin Hydrochloride and Benfotiamine in Bulk and Combined Dosage Form. Indian J of Pharmaceutical Education and Research. 2017;51(2S):S8-S16. 